\title{
Değişken Kuvvetli EMG Sinyallerinin Çok Değişkenli Görgül Kip Ayrışımı ile Analizi ve Sınıflandırılması
}

\author{
Analysis and Classification of Variational Force EMG Signals with Multivariate Empirical \\ Mode Decomposition
}

\author{
Fatih ONAY ${ }^{1}$ (i) Ahmet MERT $^{2}$ \\ ${ }^{1}$ Elektrik Elektronik Mühendisliği, İzmir Yüksek Teknoloji Enstitüsü, Urla, 35430, İzmir \\ ${ }^{2}$ Mekatronik Mühendisliği, Bursa Teknik Üniversitesi, Ylldırım, 16310, Bursa
}

$\ddot{O} \mathbf{z}$

Elektromiyografi (EMG) sinyalleri, insan-makine etkileşimli akıllı el protezlerinin kontrolünde önemli bir rol oynamaktadır. Kas aktivesinin bir sonucu olarak ortaya çıkan EMG sinyalleri, yapılan aktiviteye dair özel bilgileri kendi içerisinde ihtiva etmektedir. Dolayısıyla akıllı el protezlerinin işlevselliğinin arttrrılması, kas bölgesinden toplanan EMG sinyalinin doğru bir şekilde analiz edilip yorumlanmasına önemli ölçüde bağlıdır. Bu konsepte uygun olarak, akıllı el protezi hareketlerinin karar verme sürecinde, EMG sinyallerinin güvenilir bir şekilde kullanılabilmesi için, var olan yöntemlerin geliştirilmesi ya da bu yöntemlere üstünlük sağlayacak yeni yöntemler önerilmesi gerekmektedir. Bu çalışma kapsamında, çok kanallı EMG sinyallerinin analizinin geliştirilmesi amacıyla, çok değişkenli görgül kip ayrışımı (ÇDGKA) tabanlı öznitelik çıkarma yöntemi, geleneksel metotlara alternatif olarak sunulmuştur. Sinyali adaptif olarak salınım modlarına ayıran ÇDGKA yöntemi kullanılarak, EMG sinyalinden daha anlamlı bilgi edinilmesi amaçlanmıştır. ÇDGKA tabanlı özniteliklerin farklı el ve parmak hareketlerini ayırt etme performansı ve farklı kuvvet seviyelerine karşı gösterdiği performans incelenmiştir. Bu amaçla ampute katılımcıların artık uzuvlarından toplanan düşük, orta ve yüksek kuvvet seviyelerine ait EMG sinyalleri üzerinde ÇDGKA yöntemi uygulanarak özgül kip fonksiyonları (ÖKF) elde edilmiş̧ir. Elde edilen ÖKF'lerden çıkarılan öznitelikler kullanılarak altı farklı el ve parmak hareketi, en yakın komşu $(k$-NN), doğrusal ayrım analizi (LDA) ve destek vektör makinesi (SVM) sınıflandırıcıları kullanılarak sınıflandırılmıştır. Aynı kuvvet seviyesinde eğitilip test edilerek (Senaryo 1) ve tüm kuvvet seviyelerinde eğitilip tek bir kuvvet seviyesinde test edilerek (Senaryo 2) gerçekleştirilen sinıflandırmalar neticesinde, önerilen ÇDGKA tabanlı özniteliklerin ham sinyal tabanlı özniteliklere göre, senaryo 1 için \%10 - \%15, senaryo 2 için \%18'e kadar üstünlük sağladı̆̆ belirlenmiştir.

Anahtar kelimeler: Elektromiyografi, Çok değişkenli görgül kip ayrışımı, İnsan-Makine Etkileşimi, El protezi, Kontrol.

\begin{abstract}
Electromyography (EMG) signals play an important role in the control of human-machine interfaced smart hand prostheses. The EMG signals emerged as a result of muscle activity contain specific information about the activity. Therefore, enhancing the functionality of intelligent hand prostheses significantly depends on the precise analysis and interpretation of the EMG signals that are collected from the muscle region. In accordance with this concept, in order to use EMG signals reliably in the decision-making process of smart hand prosthesis movements, it is necessary to improve present methods or to propose new methods to be superior to these methods. In this study, multivariate empirical decomposition (MEMD) based feature extraction method is presented as an alternative to traditional methods to improve the analysis of multichannel EMG signals. It is aimed to obtain more meaningful information from EMG signals by using the MEMD method which separates the signal into adaptive oscillation modes. The performance of discriminating hand and finger movements at different force levels of the MEMD based features was investigated. For this purpose, intrinsic mode functions (IMF) were obtained by using the MEMD method on surface EMG signals of low, medium and high force levels collected from the amputated participants. The features which are extracted from IMFs, classified by $k$ nearest neighbors (k-NN), linear discriminant analysis (LDA) and support vector machines (SVM) to discriminate six hand and finger movements. Training and testing at same force level (Scheme 1) and training the classifier with all levels of force and testing it with a single level of force (Scheme 2) classification operations were performed. The proposed MEMD based features have outperformed raw signal-based features, $10 \%-15 \%$ for Scheme 1 and up to $18 \%$ for Scheme 2.
\end{abstract}

Keywords: Electromyography, Multivariate Empirical Mode Decomposition, Human-Machine Interface, Hand Prosthesis, Control.

Sorumlu Yazar: Fatih ONAY, Tel: +90 232 750-659l, e-posta: fatihonay@iyte.edu.tr

Gönderilme: 10.09.20I9, Düzenleme: I2.05.2020, Kabul: 04.06.2020 


\section{I.GİRIŞ}

İnsan vücudunda meydana gelen uzuv kayiplar1; doğuştan, sonradan yaşanan kazalar ve hastalıklar sebebiyle meydana gelebilmekte ve bunun sonucu olarak da engelli insan sayısı her geçen gün artmaktadır. Dolayısıyla, engelli insanların yaşam kalitesini arttırmak için araştırmacılar, basit ve doğal insan-makine etkileşimli cihazların gerekliliğini düşünmektedir. İnsan-makine etkileşimi için özel bir dokudan, organdan veya sinir sisteminden elde edilen elektroansefalografi (EEG) [1], elektrookülografi (EOG) [2] veya elektromiyografi (EMG) gibi çeşitli biyolojik sinyaller kullanılabilmektedir. EMG sinyallerinin diğer biyolojik sinyallere göre daha yüksek sinyal-gürültü oranına sahip olması sebebiyle, insan-makina etkileşimli güçlendirilmiş akıllı protezlerin kontrolünde EMG sinyali tercih edilir [3].

Ampute bireylerin artık uzuvlarından alınan EMG sinyalleri ile protez kontrolü gerçekleştirmek mümkündür. EMG sinyalleri, akıllı protezlerin kullanıcıya sağladığı sezgisel kontrol sayesinde karmaşık görevlerin gerçekleştirilmesine olanak sağlar. $\mathrm{Bu}$ karmaşık kontrol sürecinin geliştirilmesi oldukça önemlidir. Bu yüzden ampute bireylerin gündelik hayatta çok fonksiyonlu el ve parmak hareketlerini gerçekleştirebilmeleri için halen pratik protezlerin geliştirilmesine ihtiyaç vardır [4]. EMG sinyali, insan kasları içerisinde bulunan bireysel motor ünitelerinin aktivitesi sonucu ortaya çıkan bir işarettir. Bu işaret kas bölgelerindeki deri üzerine yerleştirilen yüzey elektrotları ya da kas dokusuna batırılan iğne benzeri elektrodlar yardımıyla toplanabilir [5]. Yapılan çalışmalar invaziv yöntemlerle invaziv olmayan yöntemlerin benzer doğrulukta sonuçlar verdiğini göstermiştir [6]. Yüzey EMG (sEMG) yöntemi, invaziv yöntemlere göre daha kolay kullanıma sahip olması nedeniyle güçlendirilmiş protezlerin kontrolünde ihtiyaç olan sinyalin toplanması için tercih edilir.

Deri yüzeyine elektrotlar yerleștirilerek toplanan EMG sinyallerini belirtmek için kullanılan sEMG, birden fazla elektrod kullanılarak da toplanabilir ve çok kanallı sEMG halini alır. sEMG sinyallerinin zaman düzlemindeki analizinde, genlik ve enerji gibi temel sinyal analiz yöntemleri kullanılırken, frekans düzlemi analizinde ise Fourier dönüşümü (FD) ve dalgacık dönüşümü (DD) gibi sinyal işleme yöntemleri kullanılmaktadır. Farklı kas hareketleri ile elde edilen işaretler arasındaki farkları tespit etmek için gelişmiş sinyal işleme teknikleri kullanılmalıdır. Ayrıca, birden fazla kas grubunun aynı anda çalıştığı hareketler için de ayırt edici özelliklerin bulunması gerekmektedir.

Akıllı el protezlerinin kontrolünde, işlem hızı bakımından zaman tabanlı özniteliklerin kullanılması tercih edilir. Fakat farklı kuvvet seviyelerindeki kas hareketlerini ayırt etme performansı bakımından, ham sinyal tabanlı özniteliklerin geliştirilmeye ihtiyacı olduğu görülmektedir [7]. Kuvvet seviyesi değişimi ile birlikte, yapılan harekete ait kas grubundaki aktif olan motor ünitesi sayısının değişmesi, aynı hareket için farklı işaretlerin ortaya çıkmasına sebep olmaktadır. Bir akıllı protezin, farklı kuvvet seviyelerinde yapılan el hareketlerini doğru bir şekilde taklit edebilmesini sağlayacak gürbüz yöntemler geliştirmek önemli bir ihtiyaçtır.

$\mathrm{Bu}$ çalışmada, doğrusal olmayan ve durağan olmayan sinyallerin işlenmesinde taban fonksiyonuna ihtiyaç duyan analitik sinyal işleme yöntemlerine alternatif olarak geliştirilen çok değişkenli görgül kip ayrışımı yöntemi (ÇDGKA) kullanılacaktır. EMG sinyali gibi doğrusal olmayan ve durağan olmayan sinyaller, önceden belirlenen bir taban fonksiyonunun karakteristiğinden farklı bir yapıya sahip olabilir bu da analizin doğru olarak yapılamamasına sebep olabilmektedir. Bu çalışmanın amacı ise, farklı kas gruplarının eș zamanlı çalıșması neticesinde olușan çok kanallı sEMG sinyallerinin ayırt edici analizini, güncel ve gelişmiş sinyal işleme yöntemi olan ÇDGKA ile gerçekleştirmektir. Ampute bireylerden toplanan çok kanallı sEMG sinyallerinin ÇDGKA ile analizi gerçekleştirilerek, sinyalin özgül kip fonksiyonları (ÖKF) elde edilecektir. Farklı bir frekans bantlarını temsil eden ÖKF'lerden çıarılan zaman tabanlı özniteliklerin kullanılmasıyla sınıflandırma işlemi yapılacaktır. Bunun neticesinde altı farklı el ve parmak hareketini temsil eden sEMG sinyallerinin daha doğru bir şekilde ayırt edilebilmesi amaçlanmıştır. Tüm bu işlemler gerçekleştirilerek ÇDGKA tabanlı özniteliklerin, farklı kuvvet seviyelerinde gerçekleştirilen kas hareketlerini ayırt etme performansı incelenecektir.

\section{MATERYAL ve YÖNTEM}

\subsection{Veri Seti}

$\mathrm{Bu}$ çalışma için kullanılan veri seti tek taraflı amputasyona sahip dokuz bireyden (7'si travmatik, 2'si doğuştan) elde edilmiştir. Tablo 1'de verilerin toplandığ 1 katılımcılara ait yaş, cinsiyet ve ampütasyon türüne ait bilgiler verilmiştir. En az sekiz kanall, örnekleme frekans $2000 \mathrm{~Hz}$ ve çözünürlüğü 16 bit olan EMG edinim sisteminin (USB-6210, National Instruments) kullanımıyla, toplamda altı farklı kavrama ve parmak hareketine ait işaretleri içeren veri seti oluşturulmuştur. Kazanç faktörü 1000 olan çok kanallı EMG yükseltici ile her bir kanal için elde edilen sinyal yükseltilmiştir. Altı farklı parmak hareketi için her bir katılımcıdan beş ila sekiz adet kayıt alınmıştır.

Tablo 1. Çalışmada yer alan katılımcıların bilgisi.

\section{Katılımeı Yaş Cinsiyet AmputeTürü}

\begin{tabular}{cccc}
\hline Ampute 1 & 25 & E & Travmatik \\
Ampute 2 & 33 & E & Travmatik
\end{tabular}




\begin{tabular}{cccc} 
Ampute 3 & 30 & $\mathrm{E}$ & Travmatik \\
Ampute 4 & 27 & $\mathrm{E}$ & Travmatik \\
Ampute 5 & 35 & $\mathrm{E}$ & Travmatik \\
Ampute 6 & 29 & $\mathrm{E}$ & Travmatik \\
Ampute 7 & 57 & $\mathrm{E}$ & Travmatik \\
Ampute 8 & 19 & $\mathrm{~K}$ & Doğuştan \\
Ampute 9 & 31 & $\mathrm{~K}$ & Doğuştan \\
\hline
\end{tabular}

Veri setindeki 6 el hareketi Şekil 1'de gösterildiği gibidir. Sırasıyla; başparmak (BP), işaret parmağı ( IP), çimdik (ÇK), tripod kavrama (TK) kanca kavrama (KK) ve küresel kavrama (KÜK) hareketleri için toplam 9 amputeden 54 farklı EMG sinyali örneği içeren veri seti bu çalışmada kullanılmıştır.

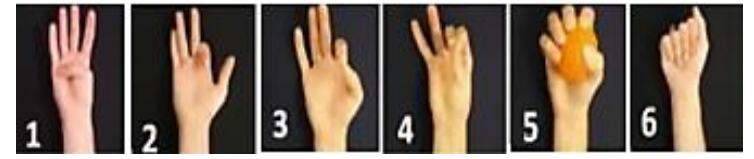

Şekil 1. Altı sınıflı veri seti el hareketleri (1: BP, 2: IPP, 3: ÇK, 4:TK, 5: KK, 6:KÜK).

Elektrodlar yerleştirilmeden önce katılımcıların derileri alkol ve aşındırıcı cilt hazırlama jeli ile temizlenmiştir. Sonrasında 8 çift $\mathrm{Ag} / \mathrm{AgCl}$ yüzey elektrodu SENIAM (Surface ElectroMyoGraphy for the Non-Invasive Assessment of Muscles) tarafindan belirlenen kıstaslara göre katılımcıların artık uzuvları üzerine tek ya da iki sıra halinde yerleştirilmiştir. Ampute 2 katılımcısına ait elektrodların yerleşimi Şekil 2'de gösterilmiştir.

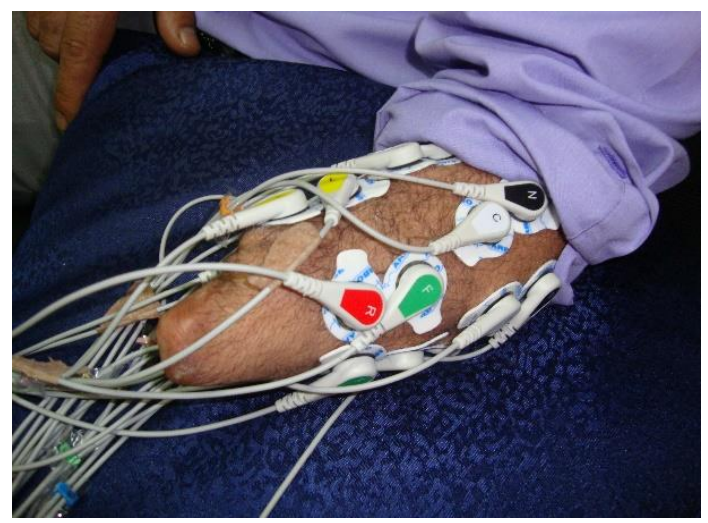

Şekil 2. Ampute 2 katılımcısına ait örnek elektrod yereleşimi

Veri toplama işlemi sırasında, katılımcılar ampütasyona uğramış uzuvlarını kullanarak istenilen hareketi yapabilmek için, bir yandan zarar görmemiş olan sağlam elleriyle de hareketleri gerçekleştirmişlerdir. Bunun yanında PC ekranında EMG kanallarını gözlemleyebilmelerini sağlayacak görseller kullanılmıştır. Böylelikle, katılımcıların istenilen kuvvet seviyesindeki hareketleri yapabilmeleri desteklenmiştir. Bu veri setinde düşük, orta ve yüksek kuvvet seviyelerine ait sinyallerin her biri için kayıtlar bulunmaktadır. Her bir el ve parmak hareketlerinin, tüm kuvvet seviyelerine ait işaretleri bu çalışma kapsamında kullanılacaktır.

\subsection{Görgül Kip Ayrışımı}

GKA Huang ve arkadaşları [8] tarafindan geliştirilmiş olup doğrusal olmayan ve durağan olmayan sinyallerin işlenmesinde başarılı sonuçlar veren bir sinyal ayrıştırma algoritmasıdır. Sinyali, kendi içinde barındırdığı sonlu sayıdaki genlik ve frekans modüleli özgül kip fonksiyonlarına (ÖKF) ayrıştıran ve doğal salınım kiplerini gösteren bir eleme sürecidir. Fourier analizinde sinüs ve kosinüs dalgalarıyla temsil edilen salınım kipleri, GKA algoritmasında özgül kip fonksiyonları ile temsil edilmektedir. GKA ile eleme süreci neticesinde elde edilen fonksiyonların özgül kip fonksiyonu olması için gerek ve yeter iki şart şu şekildedir;

1. Tüm zaman serisi boyunca mevcut olan yerel maksimum ve yerel minimum nokta sayısı sıfır geçiş sayısına eşit olmalı ya da aralarında en fazla bir fark olmalidir.

2. Yerel maksimum noktalarının oluşturduğu üst zarf ile yerel minimum noktalarının oluşturduğu alt zarfin ortalaması sıfıra eşit olmalıdır.

Yukarıda verilen şartlar ampirik olarak elde edilir bu yüzden elde edilecek ÖKF'lerin bant aralığı ve sayısı önceden kestirilemez. İkinci şartta ifade edilen yerel maksimum ve yerel minimum noktalarının ortalaması, zarf boyunca noktasal olarak hesaplanan yerel ortalamayı belirtmektedir. ÖKF'ler orijinal sinyalin farklı frekans bantlarını ve zaman ölçeklerini gösteren fonksiyonlardır. ÖKF'ler sinyalin yerel ortalamalarının hesaplanmasıyla bulunur ve böylelikle yerel ölçekte sinyalin analizi gerçekleştirilebilir. GKA algoritmasını örnek bir $x(t)$ sinyaline etkili bir şekilde uygulamak için, eleme süreci olarak adlandırılan işlem yerine getirilmelidir. İzlenmesi gereken adımlar şu şekildedir;

i. Örnek bir $x(t)$ sinyalinin tüm yerel maksimum noktaları $M(k), \mathrm{k}=1,2,3 \ldots$ ve tüm yerel minimum noktaları $M(i)$, $i=1,2,3 \ldots$ sirasiyla tespit edilir.

ii. Kübik spline interpolasyonu uygulanarak yerel maksimum ve yerel minimum noktaları birleştirilir ve sinyalin üst ve alt zarfları $e_{\text {max }}(t)$ ve $e_{\text {min }}(t)$ bulunur.

iii. Bulunan üst ve alt zarfların ortalaması $\boldsymbol{m} \boldsymbol{t}=\boldsymbol{e}_{\min } \boldsymbol{t}+\boldsymbol{e}_{\max } \boldsymbol{t} / 2$ hesaplanır. 


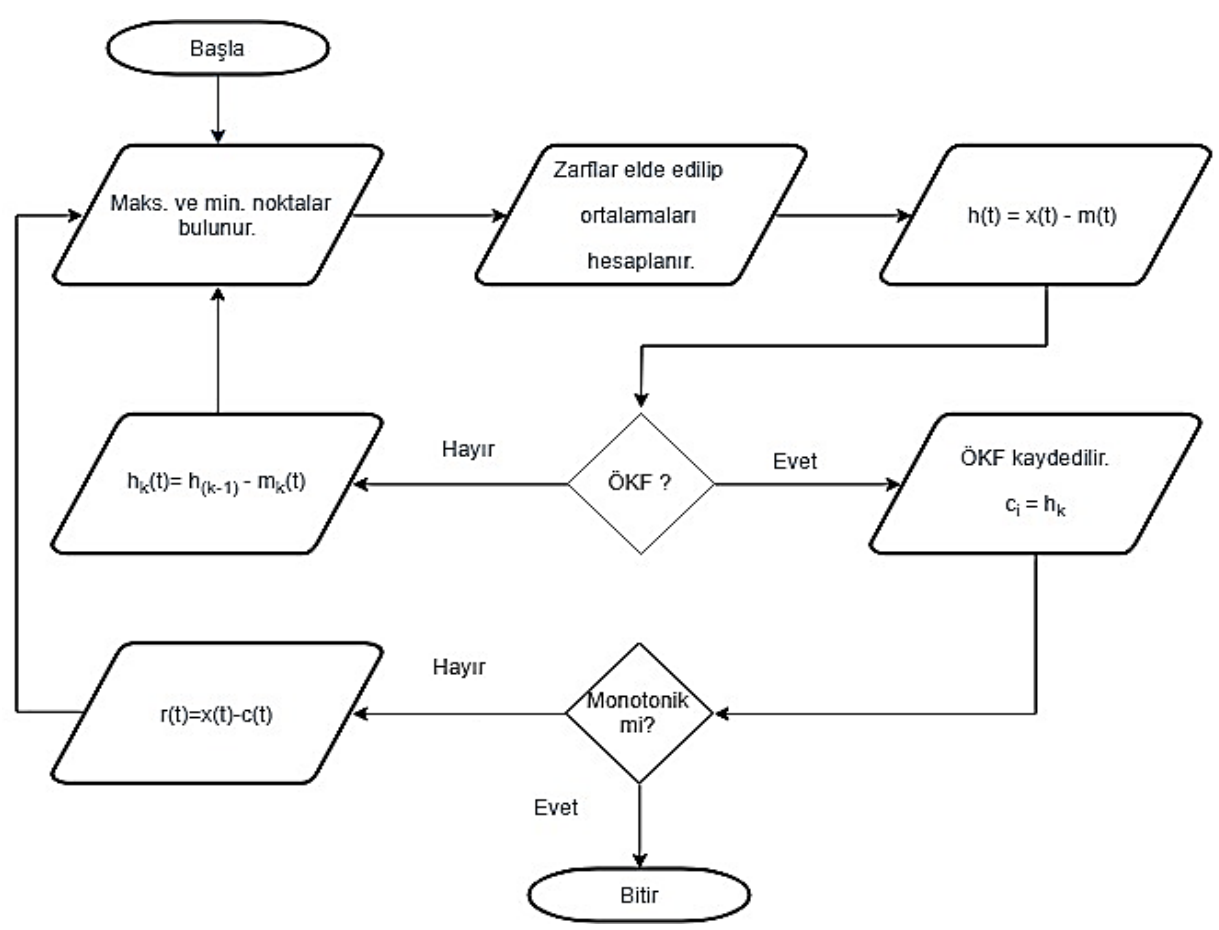

Şekil 3. GKA Algoritması Akış Diyagramı

iv. $\boldsymbol{m}(\boldsymbol{t})$ değeri ÖKF şartlarını sağlıyorsa $\boldsymbol{c}(\boldsymbol{t})=\boldsymbol{m}(\boldsymbol{t})$ ÖKF olarak saklanır. (Akış diyagramında $m(t)$ 'nin ÖKF şartlarını sağlamadığı varsayılmıştır)

v. ÖKF şartlarını sağlamaması durumunda $m(t)$ fonksiyonu sinyalin kendisinden çıkarılır. $\boldsymbol{h}_{1}(\boldsymbol{t})=\boldsymbol{x}(\boldsymbol{t})-\boldsymbol{m}_{1}(\boldsymbol{t})$ elde edilir.

vi. Bulunan $\boldsymbol{h}_{1}(\boldsymbol{t})$ ÖKF olma şartlarını yerine getirmezse, $\boldsymbol{h}_{\boldsymbol{k}}(\boldsymbol{t})=\boldsymbol{h}_{\boldsymbol{k}-1}(\boldsymbol{t})-\boldsymbol{m}_{\boldsymbol{k}}(\boldsymbol{t})$ işlemi yapılarak ilk adıma dönülür $(\mathrm{k}=1$ için $\left.\boldsymbol{h}_{\boldsymbol{k}-1}(\boldsymbol{t})=\boldsymbol{x}(\boldsymbol{t})\right) \quad$ ve $\boldsymbol{h}_{1}(\boldsymbol{t})$ üzerinde ÖKF şartları sağlanıncaya kadar eleme süreci devam eder. Böylece $\boldsymbol{h}_{1}(\boldsymbol{t})$ yeni veri olarak kabul edilir.

Eleme sürecinden ÖKF elde etme işlemi monotonik bir fonksiyon olan $\boldsymbol{r}(\boldsymbol{t})$ ifadesi elde edilinceye dek sürdürülür. Eleme sürecinin tamamlanmasıyla birlikte orijinal sinyal şu formda yazılabilir;

$$
x(t)=\sum_{k=1}^{L} c_{k}(t)+r(t)
$$

GKA algoritması, tek-kanal tabanlı bir analiz işlemi gerçekleştirmek için elverişlidir. Fakat çok kanallı sinyaller üzerinde uygulanması durumunda, kanallar arasındaki ilişkiyi dikkate almaz ve bu sebeple çok kanalı sinyallerin tutarlı bir analizini gerçekleştirmek mümkün olmayabilir. Çok kanallı sinyaller üzerinde uygulanabilecek daha kapsamlı ve tutarlı sonuçlar verebilecek bir algoritma olan ÇDGKA yöntemi bu sebeple geliştirilmiştir. $\mathrm{Bu}$ yöntem, n-boyutlu bir uzayda eleme sürecinin gerçekleştirilmesiyle bulunan ÖKF bileşenlerinin kullanılmasını esas almıştır.

\section{3. Çok Değişkenli Görgül Kip Ayrışımı}

GKA algoritması, tek-kanal tabanlı bir analiz yöntemi olup, çok kanallı EMG sinyallerini işlemek için doğrudan uygulanamaz. Ayrıca GKA algoritması, çok kanallı sinyaller için ayrıştırılmış ÖKF'lerin sayısının eşitliğini garanti etmez ve bu da çok kanallı EMG sinyal analizlerinin fiziksel olarak anlamsız olmasına neden olabilir.

Çok kanallı sinyallerin analizinde yetersiz kalan GKA yöntemine alternatif olarak Rehman ve Mandic tarafindan [9] geliştirilen çok değişkenli görgül kip ayrışımı yöntemi (ÇDGKA), tüm kanallardaki sinyallerden aynı sayıda ÖKF elde edilmesine olanak sağlar. ÇDGKA yöntemi, çok boyutlu sinyallerin salınım modlarının ortak analizini yaparak modhizalama sorununu çözmeye yardımcı olur. Bu da farklı kanallardaki aynı indeskli ÖKF'ler arasındaki frekans bantlarının tutarlılığının sağlanmasıyla gerçekleştirilir. Ayrıca frekans bantlarının birbiriyle tutarlı olması aynı sayıda ÖKF elde edilmesine katkı sağlayarak çok boyutlu sinyalin genel analizini yapmayı kolaylaştırır ve daha doğru bilgi elde edilmesini sağlar.

GKA algoritması, yerel ekstremum noktalarının interpolasyonu ile elde edilen üst ve alt zarfların ortalamasını alarak, yerel ortalama değerini kolaylıkla hesaplayabilir. Fakat çok değişkenli sinyallerin direkt olarak yerel ekstremum noktalarını bulmak kolay bir işlem değildir. $\mathrm{Bu}$ işlemin üstesinden gelebilmek maksadıyla, ÇDGKA yöntemi, çok kanallı sinyallerin n-boyutlu bir uzayda farklı doğrultulardaki gerçek değerli iz düşümlerini kullanır. Çok kanallı sinyalin farklı doğrultulardaki bu iz düşümleri genliği temsil 
eder. $\mathrm{Bu}$ iz düșümler kullanılarak sinyalin her bir kanalındaki zarfları elde edilir.

Farklı doğrultular boyunca uzanan bu zarfların, nboyutlu uzaydaki integralinin hesaplanmasiyla yerel ortalama bulunabilir. $\mathrm{Bu}$ şekilde bulunan yerel ortalamalar kullanılarak daha gürbüz bir eliminasyon işlemi yapılmış olur.

\section{4. Öznitelik Çıkarma ve Sınıflandırma}

EMG sinyalleri aracılığıyla, farklı el hareketlerinin ayrıştırılması için yapılması gereken önemli işlemlerden birisi de uygun öznitelikleri çıkarmaktır. Sınıflandırma işleminin sonucu, sınıflandırıcının kendisinden çok, kullanılan özniteliklerin etkisine bağlıdır. Öznitelik çıkarma işlemi, verinin içerisinde barındırdığı faydalı bilgileri elde etmek için kullanılan bir yöntemdir. Sinyalin kendisinden daha küçük boyutlu öznitelik vektörü elde etmek sınıflandırıcının hızını arttırarak, gerçek zamanlı uygulamaların daha iyi bir performans sergilemesini sağlayacaktır. sEMG sinyalinden çıkarılacak öznitelikler zaman tabanına, frekans tabanına ve zaman-frekans tabanına dayanan öznitelikler olmak üzere üç ana gruba ayrılabilir [10]. Zaman tabanlı öznitelikler herhangi bir transformasyon gerektirmeksizin ham EMG sinyalinden direkt olarak elde edilir. Bu özniteliklerin uygulanması kolaydır ve düşük hesaplama yükü gerektirir. Öte yandan, frekans tabanlı öznitelikle ise genellikle EMG sinyalinin güç spektral yoğunluğunun istatistiksel özelliklerini yansıtmaktadır ve kompleks işlem yükü fazladır. Protez uygulamalarında zaman tabanlı özniteliklerin iyi sonuçlar verdiği literatürde geçmiş çalışmalarda gözlemlenmiştir. [11]

Öznitelikler doğrudan EMG sinyalinin kendisinden elde edilebileceği gibi, sinyalin ayrıştırılması sonucu ortaya çıkan bileşenler kullanılarak da elde edilebilir. Fakat el hareketleri sonucunda ortaya çıkan EMG işaretleri doğrusal olmayan ve durağan olmayan bir zaman serisi olarak kabul edildiğinden, doğrusallığı ve durağanlığı varsayan ayrıştırma algoritmaları yanıltıcı sonuçlar verebilmektedir [12]. Bu yüzden ayırt edilmesi kolay öznitelikleri kullanabilmek için, EMG sinyalinin karakteristik özelliklerini dikkate alan teknikler kullanarak öznitelikler elde edilmelidir. ÇDGKA, EMG sinyallerine uygulanabilecek potansiyel bir yöntemdir. Sinyali adaptif olarak bileşenlerine ayıran ÇDGKA yöntemi, sinyalden ilgili özniteliklerin çıkarılmasına olanak sağlar ve aynı zamanda arkaplan gürültüsünün bastırılmasında ve motor ünitelerinin tespit edilmesinde de işlevsel bir rol oynar [12, 13].

Sonuç olarak ÇDGKA yönteminin kullanılması neticesinde elde edilen özgül kip fonksiyonlarından çıkarılan özniteliklerin performansı bu çalışma kapsamında incelenecektir.
$\mathrm{Bu}$ çalışmada kullanılan özniteliklere ait kısa tanımlamalar aşağıda verilmiştir.

Varyans $\left(\boldsymbol{\sigma}^{2}\right)$ : Sinyalin ortalamadan ne kadar uzaklaştığının bir ölçüsü olan standart sapmanın karesidir. Varyans, bu dalgalanmanın gücünü temsil eder. N elemanlı bir dizinin varyans hesabı;

$$
\sigma^{2}=\frac{1}{N-1} \sum_{i=1}^{N}\left|x_{i}-\mu\right|^{2}
$$

Dalga Formu Uzunluğu (WL): EMG sinyalinin her bir segmentindeki karmaşıklık ölçüsünü ifade eden bir özniteliktir. Sinyalin ardişık genlikleri $x_{n}$ ve $x_{n-1}$ arasındaki mutlak farkların toplamına eşittir.

$$
W L=\sum_{n=1}^{N}\left|x_{n}-x_{n-1}\right|
$$

Etkin Değer (RMS) : Kasılma esnasında motor ünitelerdeki fizyolojik aktivitelerin seviyesini yansıttığ için sık seçilen bir parametredir.

$$
R M S=\sqrt{\frac{1}{N} \sum_{n=1}^{N}\left|x_{n}\right|^{2}}
$$

Yukarıda verilen zaman tabanlı öznitelikler sEMG sinyallerinin analizinde sıkça kullanılmaktadır. Bu özniteliklerin ham sinyalden elde edilmiş halleri ve ÇDGKA analizi neticesinde ÖKF'lerden elde edilmiş halleri $k$-NN, SVM ve LDA sinıflandırıcıları kullanılarak sınıflandırılıp ÇDGKA tabanlı özniteliklerin sınıflandırma başarısına olan etkileri gözlemlenecektir.

ÇDGKA yöntemi sinyali frekans bantlarına ayırırken, ortaya çıkacak frekans bantlarının sayısı analiz edilen sinyalin uzunluğuna bağlıdır. Bu sebeple ilk olarak sinyalin içerdiği mümkün olan tüm frekans bantlarının elde edilmesi için $N$ adet örnek uzunluğunda sEMG sinyalleri kullanılmıştır. $\mathrm{Bu}$ işlem sonucunda elde edilen $K$ adet ÖKF bileşeninin herbirine ait ortalama frekans değerleri hesaplanır. Düşük frekans bandındaki hareket artefaktlarını bastırmak adına literatürde $10 \mathrm{~Hz}$ veya $20 \mathrm{~Hz}$ altındaki frekans bileşenlerinin filtrelenmesi önerilmiştir $[14,15,16]$. Bu yüzden ortalama frekans değeri $20 \mathrm{~Hz}$ altında olan ' $e$ ' adet ÖKF bileşeni öznitelik çıkarma sürecine dahil edilmemiştir. Böylelikle tek bir harekete ait öznitelik vektörünün uzunluğu,

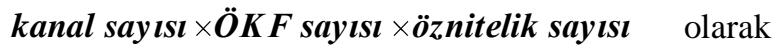
bulunur. Şekil 4 'te pencerelenen sinyalden elde edilen ÖKF'lere ait örnek gösterilmiştir. 
Veri setinde yer alan toplamda altı el ve parmak hareketine at sinyallere pencereleme işleminin uygulanmasıyla birlikte uygun uzunluktaki sinyaller ÇDGKA yöntemi ile salınım modlarına ayrıştırılır.

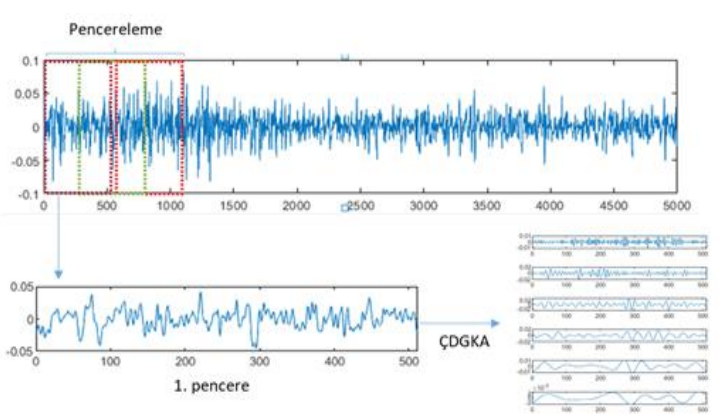

ÖKF

Şekil 4. Sinyale uygulanan pencereleme işlemi.

Tüm ÖKF'lerden öznitelik çıkarılmasıyla öznitelik vektörü elde edilir. Şekil 5'te BP hareketine ait pencerelenmiş çok kanallı sEMG sinyalinin birinci kanalına ait öznitelik çıkarma süreci gösterilmiştir. Örnek sinyal, ÇDGKA ile ÖKF'lerine ayrıştırılır ve her bir ÖKF'nin varyans, RMS, WL öznitelikleri çıkarılarak tek bir hareket örneğine ait öznitelik vektörü elde edilir.

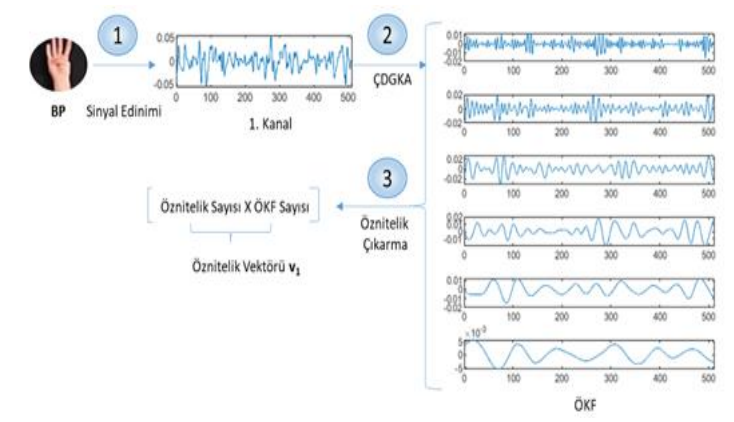

Şekil 5. Tek bir kanal için öznitelik vektörünün elde edilmesi.

\section{DENEYSEL SONUÇLAR}

\section{1. ÇDGKA Ile ÖKF'lerin Bulunması ve Eliminasyonu}

Öznitelik çıkarma ve sınıflandırma algoritmaları sEMG sinyallerinden elde edilen ÖKF'lere uygulanarak sonuçlar elde edilmiştir. Bu çalışmada etkin değer, varyans ve dalga formu uzunluğu olmak üzere üç adet zaman tabanlı öznitelik kullanılmıştır. Sınıflandırma işlemi için k-en yakın komşu ( $k$-NN), destek vektör makineleri (SVM) ve doğrusal ayırt etme analizi (LDA) algoritmaları uygulanıp test edilmiş ve doğruluk sonuçları karşılaştırılmıştır.

Şekil 6 ve Şekil 7'de ÇDGKA ile analiz edilmiş örnek bir sEMG işaretinin tek bir kanalına ait ÖKF'ler yer almaktadır. İlk ÖKF'den son ÖKF'ye doğru gidildikçe bileşenlerin periyotlarındaki değişimin artma eğiliminde olduğu görülmektedir. Her ÖKF, orijinal sinyalin farklı frekans bantlarındaki salınımlarını temsil etmektedir.

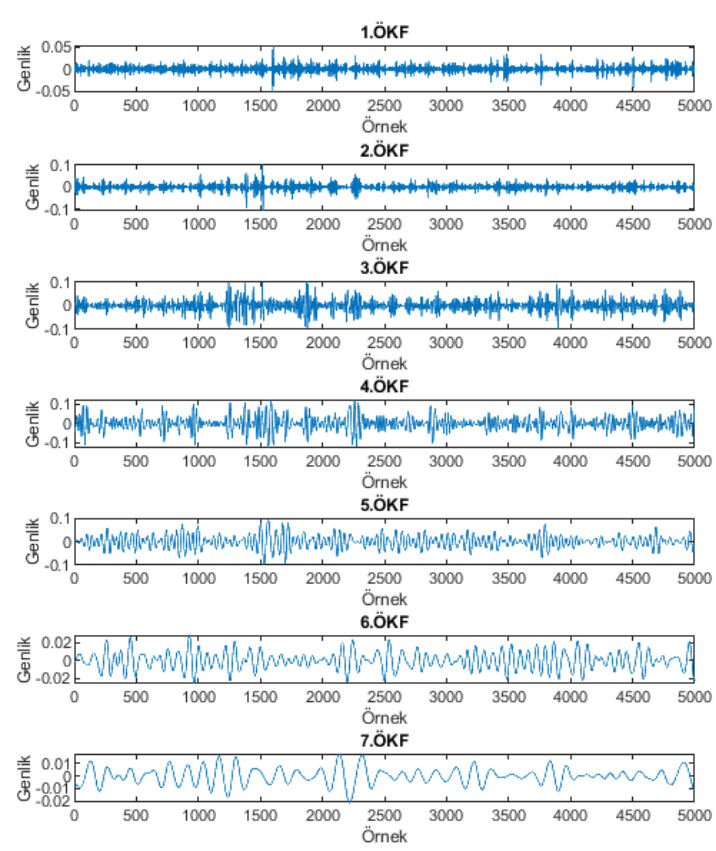

Şekil 6. İlk amputeden alınan orta kuvvet seviyesindeki BP hareketinin, birinci kanal sEMG sinyaline ait ilk 7 ÖKF bileşeni.

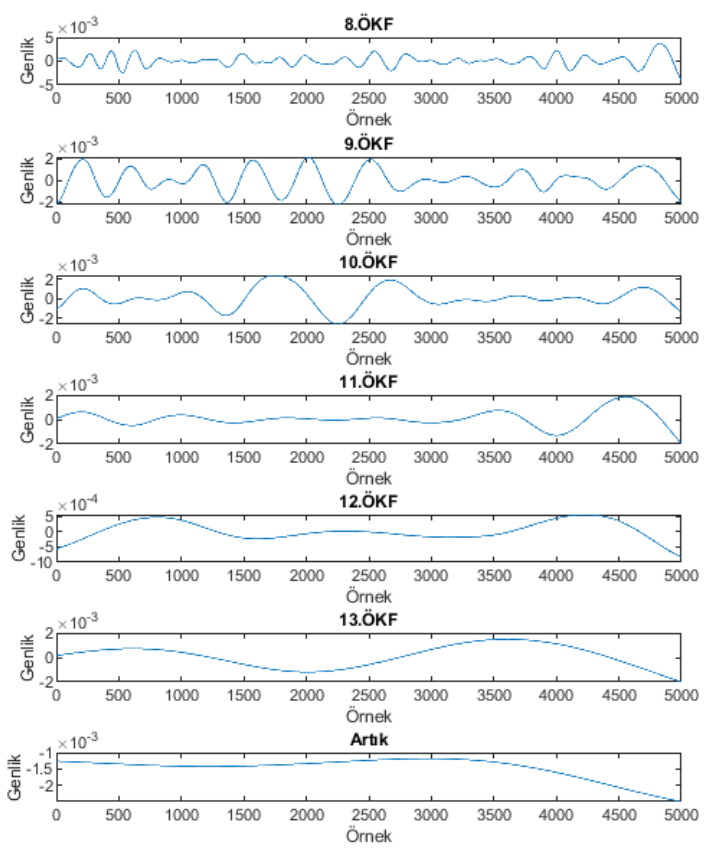

Şekil 7. İlk amputeden alınan orta kuvvet seviyesindeki BP hareketinin, ilk kanal sEMG sinyaline ait son 6 ÖKF bileşeni ve artık.

Şekil 8'de orta kuvvet seviyesine ait tüm hareketlerin bütün kanalları için hesaplanan her bir ÖKF'nin ortalama frekans değerleri verilmiştir. sEMG sinyalinin ediniminde kullanılan sekiz kanalın her birinden toplam 13 ÖKF bileşeni ve bir de artık elde edilmiştir. Her ÖKF bileşeninin farklı bir salınım modunu temsil 
ettiği verilen şekilde açıça görülmektedir. Ayrıca ÇDGKA yöntemi kanalların tümünden aynı sayıda ÖKF bileşeni çıkararak, tüm kanalların salınım modlarının aynı ölçekte hizalanmasını da sağlamaktadır. ÇDGKA algoritmasının kanallar arasındaki mod hizalama ve ÖKF'ler arasındaki mod karışımı ölçütlerini uygun bir şekilde yerine getirdiği görülmektedir.

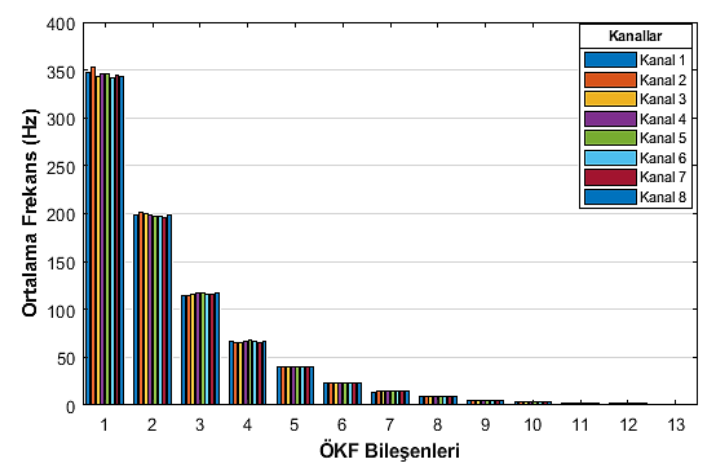

Şekil 8. Orta kuvvet seviyesindeki tüm hareketlere ait 8 kanallı sEMG sinyalinin ÇDGKA kullanılarak elde edilen ÖKF'lerinin ortalama frekans değerleri.

Şekil 9'da ÇDGKA analizi neticesinde sEMG sinyallerinden elde edilen ÖKF adetlerinin sayılarının dağılımı verilmiştir. Katılımcılardan toplanan tüm sinyaller aynı uzunlukta olmasına rağmen ÖKF sayıları aynı değildir ve 12 ile 16 arasında bir değişim göstermiştir.

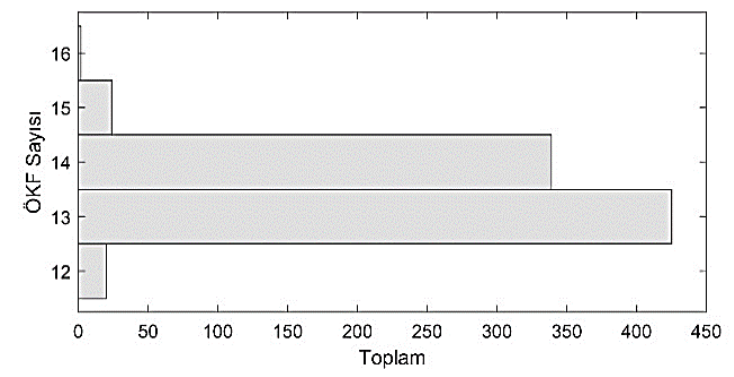

Şekil 9. Sinyallerden elde edilen ÖKF sayılarının dağılımı.

Tablo 2'de, bulunan tüm ÖKF'lerin ortalama frekans değerleri verilmiştir. Ortalama frekans değerleri ÖKF'lerin hangi bant aralığında salınım yaptığına dair bilgi vermektedir. ÇDGKA yöntemi sinyalin ayrıştırılmasında kullanılırken bununla birlikte her ÖKF'nin farklı frekans bandında salınım yapması sebebiyle sinyalin gürültüden temizlenmesi için de kullanılabilmektedir. Özellikle kayıt esnasında ve elektromanyetik girişim sebebiyle ortaya çıkan düşük frekans bandındaki gürültülerin temizlenmesi için 20 $\mathrm{Hz}$ frekans değeri altında kalan ÖKF'ler sınıflandırma performansını arttırmak için kullanılmamıştır.

sEMG sinyali kontrollü bir protez elin pratik olarak uygulamalarda kontrolünü gerçekleştirmek için, kısa örnekli sEMG sinyallerinin analizinin yapılması gerekmektedir. $\mathrm{Bu}$ kısımda ÇDGKA yönteminin bu amaca yönelik uygulanması ve performansı incelenecektir. Bir önceki kısımda sEMG sinyali üzerinde uygulanan ÇDGKA yöntemi ile bulunan ÖKF'lerin ortalama frekans değerleri incelenmiştir.

Tablo 2. Bütün kuvvet seviyelerinden elde edilen ÖKF'lerin ortalama frekans değerleri.

\begin{tabular}{cccc}
\hline \hline $\begin{array}{c}\text { Toplam ÖKF } \\
\text { Sayısı }\end{array}$ & $\begin{array}{c}\text { Düşük } \\
\text { Kuvvet } \\
(\mathbf{H z})\end{array}$ & $\begin{array}{c}\text { Orta } \\
\text { Kuvvet } \\
(\mathbf{H z})\end{array}$ & $\begin{array}{c}\text { Yüksek } \\
\text { Kuvvet } \\
(\mathbf{H z})\end{array}$ \\
\hline 1 & 348,96 & 345,85 & 345,26 \\
2 & 199,55 & 198,36 & 198,37 \\
3 & 116,56 & 115,82 & 115,90 \\
4 & 66,60 & 66,38 & 66,33 \\
5 & 40,57 & 40,44 & 40,36 \\
6 & 23,29 & 23,60 & 23,63 \\
7 & 14,02 & 14,24 & 14,21 \\
8 & 8,75 & 8,76 & 8,65 \\
9 & 5,32 & 5,34 & 5,32 \\
10 & 3,37 & 3,34 & 3,35 \\
11 & 2,17 & 2,16 & 2,15 \\
12 & 1,51 & 1,52 & 1,47 \\
13 & 1,02 & 1,01 & 0,98 \\
\hline
\end{tabular}

Elde edilen sonuçlara göre ilk 6 ÖKF'nin sınıflandırma performansında en iyi sonucu almak için yeterli olduğu gözlemlenmiştir. Bu sebeple en az 6 ÖKF elde etmeyi sağlayacak uzunluktaki sinyali kullanmak hem hesaplama yükünü azaltmaktadır hem de ÇDGKA tabanlı örüntü tanıma modelinin gerçek zamanlı olarak uygulanabilmesine yönelik performansı arttırmaktadır. Ampirik olarak gerçekleştirilen çalışmalar sonucunda $256 \mathrm{~ms}$ uzunluğundaki sinyalin en az 6 ÖKF bileşeni çıkarmayı temin ettiği görülmüştür. Pencereler bitişik olarak değil birbirleriyle 128 ms'lik bir kısımda örtüşecek biçimde ilerletilmiştir. $\mathrm{Bu}$ işleme ait süreç Şekil 'da gösterilmiştir.

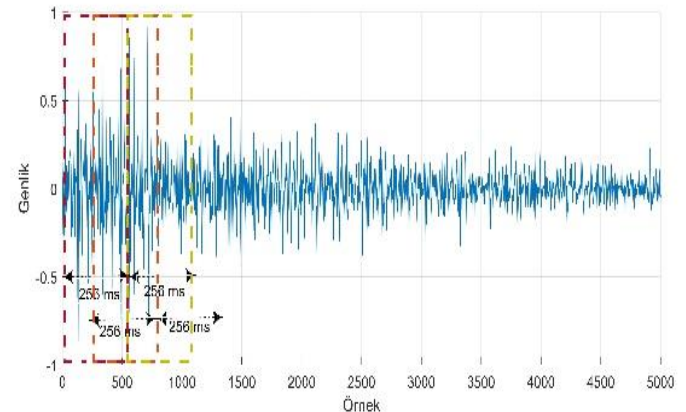

Şekil 10. Yüksek kuvvet sEMG işaretine uygulanan pencereleme işlemi.

Pencerelenen sinyaller ÇDGKA ile ÖKF bileşenlerine ayrıştırılmıştır. Şekil 11'de tek bir kanalın, bir penceresinden çıkarılan ÖKF bileşenleri gösterilmiştir. Elde edilen ÖKF'ler kanalın içerdiği salınım modlarını sırasıyla, en yüksekten başlayarak en düşük olana doğru sıralamıştır. Böylelikle sinyalin farklı salınım modları üzerinde doğrudan işlem yapabilme imkânı elde edilmiştir. $\mathrm{Bu}$ işlem her bir kanal için tekrarlanarak, her bir kanalın salınım modları ayrı ayrı bulunmuştur. 

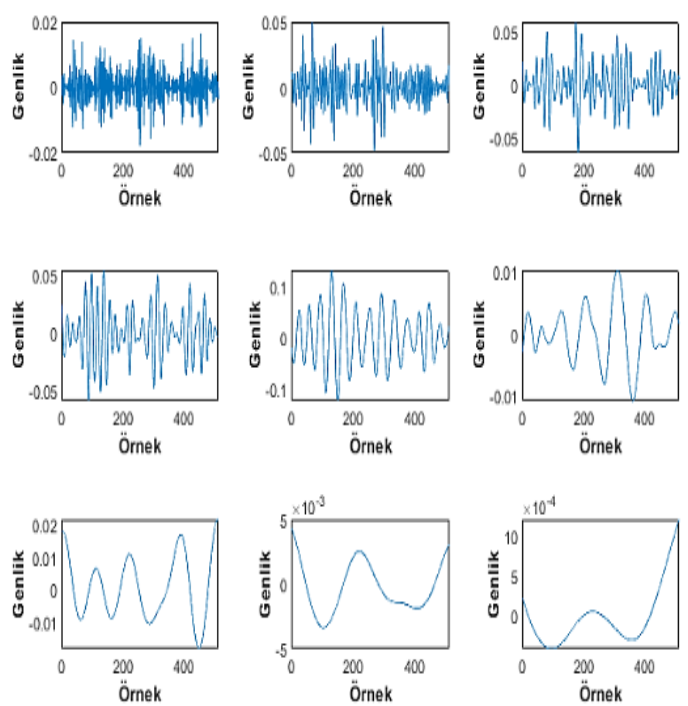

Şekil 11.Tek bir pencereden elde edilen ÖKF bileşenleri.

Ayrıca bu sinyale ait ÖKF'lerin her birine ait ortalama frekans $\left(\mathrm{Fr}_{\mathrm{m}}\right)$ değerleri Tablo 3'te yer almaktadır. Buna göre, ilk 6 ÖKF'nin $20 \mathrm{~Hz}$ üzerindeki frekans bileşenlerini temsil ettiği açıkça görülmektedir.

Tablo 3. ÖKF'lerin ortalama frekans değerleri.

\begin{tabular}{|c|c|c|c|c|c|c|c|c|}
\hline ÖKF & $\begin{array}{c}\mathbf{1 .} \\
\text { ÖKF }\end{array}$ & $\begin{array}{c}2 . \\
\text { ÖKF }\end{array}$ & $\begin{array}{c}\text { 3. } \\
\text { ÖKF }\end{array}$ & $\begin{array}{c}4 . \\
\text { ÖKF }\end{array}$ & $\begin{array}{c}5 . \\
\text { ÖKF }\end{array}$ & $\begin{array}{c}\mathbf{6} . \\
\text { ÖKF }\end{array}$ & $\begin{array}{r}7 . \\
\text { ÖK }\end{array}$ & $\begin{array}{c}8 . \\
\text { ÖKF }\end{array}$ \\
\hline & & 16 & 126.8 & 78.2 & 44.6 & 24 & 15. & 7,51 \\
\hline
\end{tabular}

Sinyal uzunluğu kısalmasına rağmen ÇDGKA yöntemi sEMG sinyalinden halen ihtiyaç duyulan frekans bantlarını çıkarabilmektedir. Sinyalin kısalması sadece düşük frekans bantlarındaki bileşenlerin elde edilememesine sebep olmuştur fakat bu bantlar sEMG sinyali analizi için gereken bileşenler değildir. Çalışmalar neticesinde pencerelerden en az 7 en fazla 11 ÖKF bileşeni elde edilmiştir ve bu da öznitelik çıkarma işlemi için uygun olan bantları kullanmak için elverişli bir imkân sunmaktadır.

\subsection{Sinıflandırma Sonuçları}

$\mathrm{Bu}$ kısımda pencerelenen sinyallerden elde edilen ÖKF'ler ve bu ÖKF'lerden elde edilen özniteliklerin, aynı kuvvet seviyesinde eğitilip test edilerek (Senaryo 1) ve tüm kuvvet seviyelerinde eğitilip tek bir kuvvet seviyesinde test edilerek (Senaryo 2) sinıflandırma işlemleri gerçekleștirilmiştir. Her bir hareket için katılımcılardan beş ile dokuz arasında farklı oturumda kayıt toplanmıştır. Sinıflandırma işleminde ise bu oturumlardan ikisi test için kullanılırken geri kalanlar ise eğitim verisi olarak kullanılmıştır.

Şekil 12'de ÇDGKA tabanlı ve ham sinyal tabanlı özniteliklerin Senaryo 1 için sınıflandırma sonuçları k$\mathrm{NN}$, LDA ve SVM için üç farklı kuvvet seviyesine göre gösteriliş̧ir.

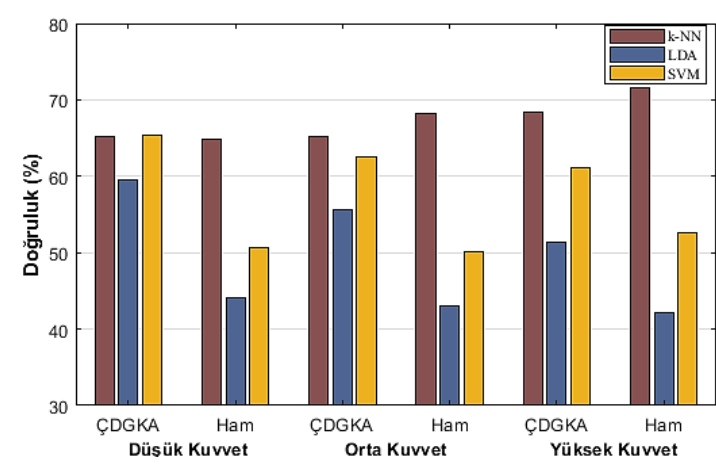

Şekil 3. Aynı kuvvet eğitim ve test kümesi kullanılarak elde edilen sınıflandırma sonuçları.

Tablo 4'te pencereleme yöntemiyle elde edilen örnekler kullanılarak yapılan sinıflandırma sonuçlarının sayısal değerleri verilmiştir. Tüm kuvvet seviyeleri için, ÇDGKA tabanlı öznitelik çıkarma yönteminin, ham veriden doğrudan öznitelik çıkarma yöntemine göre LDA ve SVM sinıflandırıcısı için ortalama \%12 daha başarılı olduğu görülmektedir. Düşük kuvvet seviyesinde k-NN sinıflandırıcının ÇDGKA tabanlı öznitelikleri ayırt etme performansı önde olsa da orta ve yüksek kuvvetlerin ayrıştırılmasında ÇDGKA tabanlı öznitelikler daha kötü bir performans göstermiştir.

Farklı kuvvet seviyelerinde ortaya çıkan sEMG işaretinin ayrış̧ırılmasına yönelik yapılan sınıflandırma işlemlerinde kullanılan özniteliklerin performansı, Senaryo 2 için de ayrıca test edilmiştir. Tüm kuvvet seviyelerine ait öznitelikler kullanılarak eğitim işlemi yapılmış ve tek bir kuvvet seviyesine ait öznitelikler ile test edilerek sınıflandırma işlemi gerçekleştirilmiştir.

Şekil 13'te ÇDGKA tabanlı ve ham sinyal tabanlı özniteliklerin Senaryo 2 için sınıflandırma sonuçları $k$ $\mathrm{NN}$, LDA ve SVM için üç farklı kuvvet seviyesine göre gösterilmiştir.

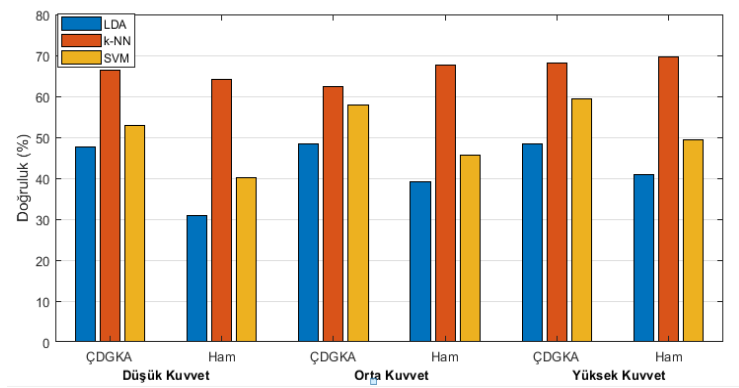

Şekil 13. Tüm kuvvet eğitim ve tek kuvvet test kümesi kullanılarak elde edilen sınıflandırma sonuçları.

Tablo 5'te ham sinyal tabanlı özniteliklerin ve ÇDGKA tabanlı özniteliklerin sinıflandırılması neticesinde bulunan sonuçlar üç farklı kuvvet seviyesi için verilmiş̧ir. Illk senaryoya benzer bir şekilde tüm kuvvet seviyelerinde geçerli olmak üzere ÇDGKA tabanlı öznitelikler, ham tabanlı özniteliklere göre LDA sınıflandırıcısı için ortalama \%12 ve SVM sınıflandırıcı için ortalama \%11 daha başarılı bir performans göstermiştir. Düşük kuvvet seviyesinde k-NN ile 
yapılan ayırt etme işleminde ÇDGKA tabanlı öznitelikler, ham tabanlı özniteliklere üstünlük sağlamış olsa da orta ve yüksek kuvvet seviyelerinde geride kalmıştır.

Tablo 5. Tüm kuvvet seviyeleri ile eğitim ve tek bir kuvvet seviyesi ile test için sinıflandırma sonuçları.

\begin{tabular}{lcccc}
\hline \hline Kuvvet & Yöntem & $\boldsymbol{k}$-NN & LDA & SVM \\
\hline Düşük Kuvvet & ÇDGKA & $\mathbf{6 6 , 4 6}$ & $\mathbf{4 7 , 6 9}$ & $\mathbf{5 2 , 7 8}$ \\
& Ham & $\mathbf{6 4 , 0 4}$ & 30,86 & 40,17 \\
Orta Kuvvet & ÇDGKA & $\mathbf{6 2 , 4 5}$ & $\mathbf{4 8 , 4 6}$ & $\mathbf{5 7 , 7 7}$ \\
& Ham & 67,54 & 39,09 & 45,73 \\
Yüksek Kuvvet & ÇDGKA & $\mathbf{6 8 , 0 6}$ & $\mathbf{4 8 , 4 1}$ & $\mathbf{5 9 , 4 1}$ \\
& Ham & 69,75 & 40,95 & 49,28 \\
\hline
\end{tabular}

Şekil 14'te ise sirasıyla LDA ve SVM sınıflandırıcılarına ait düşük, orta ve yüksek kuvvetlerin genel sınıflandırma sonuçları verilmiştir. Her bir el hareketinin, CDGKA tabanlı ve ham tabanlı özniteliklere göre sınıflandırma sonuçları karışıklık matrislerinde yer almaktadir.

\begin{tabular}{|c|c|c|c|c|c|c|c|}
\hline & & & Kar & iklık M & trisi & & \\
\hline$B P$ & 535 & 18 & 271 & 19 & 32 & 142 & $52.6 \%$ \\
\hline & & & & & & & \\
\hline jp & 25 & 555 & 52 & 204 & 196 & 142 & $47.3 \%$ \\
\hline & 63 & 423 & 104 & 248 & 297 & 135 & $33.3 \%$ \\
\hline & 223 & 55 & 487 & 15 & 50 & 74 & $53.9 \%$ \\
\hline çর & 160 & 61 & 300 & 37 & 54 & 115 & $41.3 \%$ \\
\hline TK & 27 & 112 & 8 & 469 & 75 & 25 & $65.5 \%$ \\
\hline & 107 & 146 & 37 & 419 & 84 & 83 & $47.8 \%$ \\
\hline KK & $\begin{array}{l}35 \\
45\end{array}$ & $\begin{array}{l}132 \\
237\end{array}$ & $\begin{array}{l}42 \\
65\end{array}$ & $\begin{array}{l}159 \\
140\end{array}$ & $\begin{array}{l}438 \\
361\end{array}$ & $\begin{array}{l}263 \\
275\end{array}$ & $\begin{array}{l}41.0 \% \\
32.1 \%\end{array}$ \\
\hline KüKK & 127 & 100 & 112 & 106 & 181 & 326 & $34.2 \%$ \\
\hline & 109 & 27 & 147 & 74 & 59 & 165 & $28,4 \%$ \\
\hline & $55.0 \%$ & $\begin{array}{l}57.1 \% \\
\end{array}$ & $50.1 \%$ & $48.3 \%$ & $45.1 \%$ & $33.5 \%$ & $48.2 \%$ \\
\hline & $50.2 \%$ & $43 . .5 \%$ & $30.9 \%$ & $43.1 \%$ & $37.1 \%$ & $17.0 \%$ & $37.0 \%$ \\
\hline & $8^{8}$ & $\$$ & ct & 사 & tt & $0^{t+}$ & \\
\hline & & & & Gerçe & & & \\
\hline
\end{tabular}

(a) LDA siniflandirma

\begin{tabular}{|c|c|c|c|c|c|c|c|}
\hline & & & & șklık M & trisi & & \\
\hline BP & $\begin{array}{l}590 \\
499\end{array}$ & $\begin{array}{l}31 \\
55\end{array}$ & $\begin{array}{l}237 \\
284\end{array}$ & $\begin{array}{l}12 \\
31\end{array}$ & $\begin{array}{l}42 \\
45\end{array}$ & $\begin{array}{c}83 \\
135\end{array}$ & $\begin{array}{l}59.3 \% \\
47.6 \%\end{array}$ \\
\hline ip & $\begin{array}{l}9 \\
54\end{array}$ & $\begin{array}{l}575 \\
495\end{array}$ & $\begin{array}{l}53 \\
64\end{array}$ & $\begin{array}{l}109 \\
145\end{array}$ & $\begin{array}{l}182 \\
198\end{array}$ & $\begin{array}{l}123 \\
201\end{array}$ & $\begin{array}{l}54.7 \% \\
42.8 \%\end{array}$ \\
\hline ÇK & $\begin{array}{l}233 \\
217\end{array}$ & $\begin{array}{l}38 \\
70\end{array}$ & $\begin{array}{l}549 \\
456\end{array}$ & $\begin{array}{l}34 \\
59\end{array}$ & $\begin{array}{c}52 \\
108\end{array}$ & $\begin{array}{c}87 \\
142\end{array}$ & $\begin{array}{l}55.3 \% \\
43.3 \%\end{array}$ \\
\hline TK & $\begin{array}{l}27 \\
84\end{array}$ & $\begin{array}{l}137 \\
147\end{array}$ & $\begin{array}{l}25 \\
45\end{array}$ & $\begin{array}{l}673 \\
569\end{array}$ & $\begin{array}{l}116 \\
168\end{array}$ & $\begin{array}{l}42 \\
88\end{array}$ & $\begin{array}{l}66.0 \% \\
51.7 \%\end{array}$ \\
\hline KK & $\begin{array}{l}43 \\
45\end{array}$ & $\begin{array}{l}128 \\
145\end{array}$ & $\begin{array}{l}35 \\
50\end{array}$ & $\begin{array}{c}87 \\
111\end{array}$ & $\begin{array}{l}449 \\
363\end{array}$ & $\begin{array}{l}169 \\
160\end{array}$ & $\begin{array}{l}49.3 \% \\
41.5 \%\end{array}$ \\
\hline КÜK & $\begin{array}{l}70 \\
73\end{array}$ & $\begin{array}{l}63 \\
60\end{array}$ & $\begin{array}{l}73 \\
73\end{array}$ & $\begin{array}{l}57 \\
57\end{array}$ & $\begin{array}{c}131 \\
90\end{array}$ & $\begin{array}{l}468 \\
246\end{array}$ & $\begin{array}{l}54.3 \% \\
41.1 \%\end{array}$ \\
\hline & $\begin{array}{l}60.7 \% \\
51.3 \%\end{array}$ & $\begin{array}{l}59.2 \% \\
50.9 \%\end{array}$ & $\begin{array}{l}\mathbf{5 6 . 5 \%} \\
46.9 \%\end{array}$ & $\begin{array}{l}69.2 \% \\
58.5 \%\end{array}$ & $\begin{array}{l}46.2 \% \\
37.3 \%\end{array}$ & $\begin{array}{l}48.1 \% \\
25.3 \%\end{array}$ & $\begin{array}{l}56.7 \% \\
45.1 \%\end{array}$ \\
\hline & $8^{8}$ & 8 & $a_{t}^{+}$ & st & सt & $p^{j t}$ & \\
\hline
\end{tabular}

(b) SVM siniflandirma

Şekil 14. Üç Kuvvet için ortalama sınıflandırma sonuçları

\section{SONUÇ VE TARTIŞMA}

Bu çalışma kapsamında, EMG sinyallerini işlemek ve özelliklerini tespit etmek için kullanılan ÇDGKA yöntemi ile elde edilen öznitelikler, el ve parmak hareketlerini ayırt etme performansı bakımından ham sinyal tabanlı öznitelikler ile karşılaştırılmıştır. Bu karşılaştırmanın sonucunda elde edilen sonuçlar, protez ellerin kontrolüne yönelik EMG sinyallerini ayrıştırmak ve analiz etmek için yeni bir yöntemin geliştirilmesine olanak sağlamıştır.

EMG sinyallerinin çok kanallı olarak analizini gerçekleştirmek ve farklı kuvvet seviyelerindeki el hareketlerine ait sinyalleri de kullanarak altı farklı hareketi ayırt edebilmek için, özniteliklerin geliştirilmesi amaçlanmıştır. $\mathrm{Bu}$ sebeple sinyaller ÇDGKA yöntemi ile özgül kip fonksiyonlarına ayrıştırılarak, sinyalin yerel ölçekte her bir salınım modunun analizini yapmak mümkün kılınmıştır. Sinyale ait tüm salınım modları ayrı ayrı öznitelik çıkarmak için kullanılmıştır. Ayrıca farklı salınım modları arasinda meydana gelebilecek mod karışımından kaçınıldığı ve kanallar arası mod hizalamasının düzgün bir şekilde gerçekleştirildiği gözlemlenmiştir.

ÇDGKA yönteminin, sinyalin uzunluğuna göre farklı sayıda ÖKF çıkarması sebebiyle, sinyalin lokal bilgilerini kaybetmeden uygun uzunluktaki sinyali seçmek için EMG gerekli minimum ÖKF sayısı tespit edilerek işlem hızlandırılmıştır. ÖKF'lerin her birinden öznitelikler çıkarılmıştır. Bu şekilde genel bir şablon oluşturularak, ÇDGKA yönteminin gerçek zamanlı uygulamalarda, her işleme aşamasında sinyale ait en uygun ÖKF'lerin belirlenmesine yönelik işlem yoğunluğundan kaçınılması amaçlanmıştır. ÇDGKA tabanlı öznitelikler ile sinıflandırılan farklı kuvvet seviyelerindeki çok kanallı sEMG sinyalleri, ham sinyal tabanlı özniteliklere göre senaryo 1 için \%10$\% 15$, senaryo 2 için \%18'e kadar üstünlük sağlamıştır.

Sonuç olarak ÇDGKA yöntemi tabanlı özniteliklerin işlevselliği sınıflandırma performansı açısından gösterilmiştir.

$\mathrm{Bu}$ özniteliklerin, ham sinyal tabanlı özniteliklere sağladığı üstünlük açıkça gösterilmiştir. Fakat bu üstünlüğe rağmen ÇDGKA yöntemi tabanlı öznitelik çıkarma yönteminin, halen geliştirilmeye ihtiyacı olduğu görülmektedir. Bunun yanında gerçek zamanlı uygulamalara yönelik hesaplama yükünün azaltılması için de çalışmalara ihtiyaç vardır. Böylelikle akıllı el protezlerinin güvenilirliğinin arttırılması ve geleceğe yönelik olarak bu protezlerin, ampute bireyler için uzuv kayıplarının eksikliğini temin etmesi umulmaktadır.

\section{TEŞEKKÜR}

$\mathrm{Bu}$ çalışma Bursa Teknik Üniversitesi Bilimsel Araştırma Projeleri 182L21 numaralı yüksek lisans tez 
projesi ile desteklenmiştir.

\section{KAYNAKLAR}

[1] Bright, D., Nair, A., Salvekar, D., \& Bhisikar, S. (2016). EEG-based brain controlled prosthetic arm. In Conference on Advances in Signal Processing, CASP 2016.

[2] Barea, R., Boquete, L., Mazo, M., Lopez, E., \& Bergasa, L. M. (2000). EOG guidance of a wheelchair using neural networks. Proceedings 15th International Conference on Pattern Recognition. ICPR-2000.

[3] Hakonen, M., Piitulainen, H., \& Visala, A. (2015). Current state of digital signal processing in myoelectric interfaces and related applications. Biomedical Signal Processing and Control, 18, 334-359.

[4] Bock, O. (2006). Myoelectric Control Of Powered Upper- Limb Prostheses.

[5] Stashuk, D. (2001). EMG signal decomposition: How can it be accomplished and used. Journal of Electromyography and Kinesiology, 11(3), 151173.

[6] Hargrove, L. J., Englehart, K., \& Hudgins, B. (2007). A comparison of surface and intramuscular myoelectric signal classification. IEEE Transactions on Biomedical Engineering, 54(5), 847-853

[7] Al-Timemy, A. H., Khushaba, R. N., Bugmann, G., \& Escudero, J. (2016). Improving the Performance Against Force Variation of EMG Controlled Multifunctional Upper-Limb Prostheses for Transradial Amputees. IEEE Transactions on Neural Systems and Rehabilitation Engineering, 24(6), 650-661.

[8] Huang, N. E., Shen, Z., Long, S. R., Wu, M. C., Shih, Zheng. (1998). The empirical mode decomposition and the Hilbert spectrum for nonlinear and non-stationary time series analysis. Proceedings of the Royal Society A: Mathematical, Physical and Engineering
Sciences, 454(1971), 903-995.

[9] Rehman, N., \& Mandic, D. P. (2010a). Multivariate empirical mode decomposition. Proceedings of the Royal Society A: Mathematical, Physical and Engineering Sciences, 466(2117), 1291-1302.

[10] Altamirano, A. A. (2017). EMG Pattern Prediction for Upper Limb Movements Based on Wavelet and Hilbert-Huang Transform. (Doctoral dissertation, Université de Lorraine; Instituto Politécnico Nacional (México)).

[11] Phinyomark, A., Quaine, F., Charbonnier, S., Serviere, C., Tarpin-Bernard, F., \& Laurillau, Y. (2013). EMG feature evaluation for improving myoelectric pattern recognition robustness. Expert Systems with applications, 40(12), 48324840.

[12] Sapsanis, C., Georgoulas, G., Tzes, A., \& Member, S. (2013). A. EMG Data Collection, 716-722

[13] Ruiz-Olaya, A. F., \& Lopez-Delis, A. (2013). Surface EMG signal analysis based on the empirical mode decomposition for human-robot interaction. In Symposium of Signals, Images and Artificial Vision - 2013, STSIVA 2013.

[14] Sapsanis, C., Georgoulas, G., Tzes, A., \& Lymberopoulos, D. (2013). Improving EMG based Classification of basic hand movements using EMD. 2013 35th Annual International Conference of the IEEE Engineering in Medicine and Biology Society (EMBC), 5754-5757.

[15] De Luca, C. J., Donald Gilmore, L., Kuznetsov, M., \& Roy, S. H. (2010). Filtering the surface EMG signal: Movement artifact and baseline noise contamination. Journal of Biomechanics, 43(8), 1573-1579.

[16] Myers, L. J., Lowery, M., O’Malley, M., Vaughan, C. L., Heneghan, C., St. Clair Gibson, A., Sreenivasan, R. (2003). Rectification and nonlinear pre-processing of EMG signals for corticomuscular analysis. Journal of Neuroscience Methods, 124(2), 157-165. 